Rademakers, J., Nijman, J., Brabers, A.E.M., Jong, J.D. de, Hendriks, M. The relative effect of health literacy and patient activation on provider choice in the Netherlands. Health Policy: 2014, ) 114(2-3), 200-206

\begin{tabular}{|l|l|}
$\begin{array}{l}\text { Postprint } \\
\text { Version }\end{array}$ & 1.0 \\
\hline Journal website & $\underline{\text { http://www.healthpolicyirnl.com/article/S0168-8510(13)00209-1/abstract }}$ \\
\hline Pubmed link & $\underline{\text { http://www.ncbi.nlm.nih.gov/pubmed/23972373 }}$ \\
\hline DOI & $10.1016 / j . h e a l t h p o l .2013 .07 .020$ \\
\hline
\end{tabular}

This is a NIVEL certified Post Print, more info at http://www.nivel.eu

\title{
The relative effect of health literacy and patient activation on provider choice in the Netherlands
}

\author{
JANY RADEMAKERS * , JeSSICA NiJMAN, ANNE E.M. BRABERS, JUdith D. DE JONG, \\ MICHELLE HENDRIKS
}

NIVEL - Netherlands Institute for Health Services Research, Utrecht, The Netherlands

\begin{abstract}
A B S T R A C T
Active provider choice by patients has become an important policy theme in western, countries over the last decades. However, not many patients and consumers exercise their right to, choose. Both health literacy and patient activation are likely to have an impact on the choice process. In, this article the relative effect of health literacy and patient activation on provider choice in the, Netherlands is studied. A questionnaire was sent to a representative sample of 2000 Dutch citizens. The questionnaire, included a measure of functional health literacy, the Dutch version of the Patient Activation Measure, and questions assessing active provider choice, reasons not to engage in it and other ways of provider, selection. The majority of respondents (59.6\%) would not search for information on the basis of which they, could select the best provider or hospital. Most people rely on their general practitioner's advice. Both, low literacy and lower patient activation levels were negatively associated with active provider choice. In a regression analysis gender, education and patient activation proved the most important, predictors. The policy focus on active provider choice might result in inequity, with men, less educated, and less activated people being at a disadvantage.
\end{abstract}

\section{INTRODUCTION}

Over the last decades health care policies in many countries have shifted from a supply to a demand or consumer driven organization of health care services. In the Netherlands, this has led to a major change in the health care system in 2006, in which regulated competition between health care providers became the central concept. Three separate markets in health care were introduced: (1) the health care insurance market, where individuals can choose between health plans, (2) the health care purchasing market, where health care is purchased by insurers, and (3) the 
Rademakers, J., Nijman, J., Brabers, A.E.M., Jong, J.D. de, Hendriks, M. The relative effect of health literacy and patient activation on provider choice in the Netherlands. Health Policy: 2014 114(2-3), 200-206

health care provision market, where people can choose between providers [5,6]. In the present article, we focus on this last 'market', where patients (or, in more economic terms, health care consumers) are expected to make active and wellinformed choices for a specific hospital or provider. In other western countries such as the USA, Great Britain, Denmark, Norway and Sweden patient choice has become an important policy theme as well $[4,9,25]$. Provider choice by patients is considered to be both a goal in itself, positively associated with autonomy and selfdetermination, and according to the policy theory behind Dutch legislation also a means to enhance competition between providers, thus increasing the quality of care. Patients and potential health care consumers can switch between health care providers, thus influencing market shares. They can also influence the quality of care, since their experiences and patient reported outcomes are more and more regarded as significant quality indicators.

This dual process in which patients can have a positive influence on quality of care has been described by Berwick et al. [1]. The model was developed in the USA but is also applicable in other countries with sufficient availability of health care services and where patients have the right to choose their own providers.

However, though patients and consumers have the right and are actually encouraged to make active choices, e.g. by providing comparative quality information on provider performance, not many of them actually do so [8,14]. Fotaki et al. [8] conclude from their review that choosing between hospitals or primary care providers is not a high priority for the general public in the UK, other European countries and the USA, except where local services are poor (e.g. long waiting times). Grol and Faber [14] reported that over a period of 2 years, only $18 \%$ of a sample of Dutch adults said they had looked for information on the quality of hospitals and $13 \%$ for information on the quality of individual doc- tors in the process of making an informed provider choice. Many patients (34-70\%) rely on the choice of their GP for a specific medical specialist or hospital and, at least for relative simple procedures, they prefer to go to the nearest provider [12,13,26,27]. Whether patients and consumers exercise their right to provider choice varies in the general population. Those who do make active choices are usually younger, in better health, more affluent and better educated $[7,8,26]$. Most probably these sociodemographic patient characteristics reflect differences in the motivation and ability of people to be an active participant regarding their own health care decisions and the competencies they have to access and use comparative quality information and make informed choices. Important theoretical concepts in this context are health literacy and patient activation. Functional health literacy means having sufficient basic skills in reading and writing to be able to function effectively in everyday situations.

Adequate functional health literacy is positively associated with the seeking, use and comprehension of comparative health care information $[21,15]$ which are important for making an informed provider selection. From a recent international comparative European study [23] we know that the percentage of the population with limited health literacy skills varies between

28.7\% (the Netherlands) to $62.1 \%$ (Bulgaria). In this survey, health literacy was defined as four different stages of information processing (access, understand, appraise, apply) related to health relevant decision-making and tasks, which is broader than the basic functional definition, but still focused on cognitive skills. A different and broader perspective on patients' competencies is captured in the 
Rademakers, J., Nijman, J., Brabers, A.E.M., Jong, J.D. de, Hendriks, M. The relative effect of health literacy and patient activation on provider choice in the Netherlands. Health Policy: 2014 114(2-3), 200-206

concept of patient activation. Patient activation is defined as having the knowledge, skills, confidence and behaviours needed for managing one's own health and health care [16]. A 13-item instrument that measures the concept of patient activation is the Patient Activation Measure (PAM-13). Based on their PAM score, people can be assigned to one of four progressively higher levels of activation. At the lowest levels, people tend to be passive, lack basic knowl- edge, and may not feel confident enough to play an active role regarding their own health and health care. From the third level upward, people will take action but may still lack confidence and skills, especially to maintain adequate behaviour in times of stress. A higher patient activation score is positively associated with various health related behaviours including the seeking and use of health care information [18,17,21].

In a Dutch sample, $22.0 \%$ of the general population scored within the first (and lowest) activation level and $25.9 \%$ in level 2 ([21]; same sample as this study), indicating that one-fourth to half of the general population might have difficulties in being an active participant in health care.

Both an individual's level of health literacy and of patient activation is likely to have an impact on their provider choice process. Since the government in the Netherlands invests heavily in the development of quality indicators and the publication of comparative health information, we have recently performed a study on the relative influence of health literacy and patient activation on the seeking, use and comprehension of health care information [21]. From this study we know that patient activation proved to be a stronger predictor for seeking and using health information than functional health literacy. The relative effect of health literacy and patient activation on provider choice, however, has not yet been studied, neither in- or outside the Netherlands. Only recently measures of health literacy and patient activation have been translated in Dutch and validated in the Netherlands [10,24]. Therefore, this study is innovative and the first to establish whether and how health literacy and patient activation affect patient choice in the Netherlands. Our main research questions in this article are:

a. How do health literacy and patient activation affect provider choice?

b. What are the reasons for consumers not to engage in active provider choice, and do these reasons differ by level of health literacy or patient activation?

c. How do consumers who are not active choosers select a provider (hospital or medical specialist), and does this process differ by level of health literacy or patient activation?

Since provider choice is regarded an important policy goal, it is imperative to have more insight in the mechanisms that drive the process and establish whether the focus on cognitive, rational choice behaviour matches the reality of patients and consumers. Given the fact that a large proportion of the population is not activated and lacks health literacy skills the focus on active provider choice might contribute to inequity in health care (e.g. in quality of care received) and further polarization in patient participation and access and use of health care services [3]. 
Rademakers, J., Nijman, J., Brabers, A.E.M., Jong, J.D. de, Hendriks, M. The relative effect of health literacy and patient activation on provider choice in the Netherlands. Health Policy: 2014, ) 114(2-3), 200-206

\section{MATERials AND MEthodS}

\subsection{Subjects}

The study sample consisted of members of the 'Dutch Health Care Consumer Panel' of NIVEL, the Netherlands Institute for Health Services Research. This panel consists of about 6000 people aged 18 years and older [2].

From the panel, samples can be drawn that are representative of the general population for age and gender.

Migrants are underrepresented in the panel. Members of the panel receive a questionnaire four times a year and can quit the panel any time. Every two years, one third of the panel is renewed. The protection of the collected data was laid down in privacy regulations, safeguarding ethical consent, and registered with the Dutch Data Protection Authority (nr. 1262949).

In March 2011, a questionnaire was sent to one-third $(\mathrm{N}=2000)$ of the panel. A written questionnaire was sent to 928 members, while 1.072 members received an invitation for an online questionnaire (according to their previously stated preference).

\subsection{Measures}

The questionnaire included, amongst other health related questions, a measure of functional health literacy (SBSQ-D, Dutch version of the Set of Brief Screening Questions, [10]), the Dutch version of the Patient Activation Measure (PAM 13Dutch, [24]), and a set of questions assessing active provider choice, reasons not to engage in it and other ways of provider selection.

\subsection{Provider choice}

Provider choice was assessed through a set of three multiple choice questions: (1) "If the general practitioner referred you to a medical specialist, would you search for information on the basis of which you yourself could select the best hospital or medical specialist?" (no/yes). (2) "What is the reason you would not seek for information to make a decision about a hospital or medical specialist?” (I already know which hospital or specialist I will visit, I do not know where to base my decision on, I do not know how to judge the information) and (3) "How would you then choose a hospital or medical specialist?" (I choose the hospital or specialist which/who my general practitioner advices me, I choose the hospital or specialist which/who I have good experiences with, I choose the hospital or specialist which/who is the nearest by). With questions (2) and (3) respondents could indicate multiple answers. Question 1 was used as an indicator of active provider choice.

\subsection{Health literacy}

The SBSQ-D consists of three questions: (1) "How often do you have someone help you read materials?”, (2) "How confident are you filling out medical forms by yourself?” and (3) "How often do you have problems learning about your medical condition because of difficulty understanding written information?" [10]. Questions (1) and (3) have response options never, occasionally, sometimes, often or always. For question (2) the response options are extremely, quite a bit, somewhat, a little bit and not at all. Answers were scored on a scale from 0 to 4 where 0 represents 
Rademakers, J., Nijman, J., Brabers, A.E.M., Jong, J.D. de, Hendriks, M. The relative effect of health literacy and patient activation on provider choice in the Netherlands. Health Policy: 2014, ) 114(2-3), 200-206

answers indicating lower and 4 indicating higher levels of literacy. The total possible score was 12. Lacking an absolute norm for low and high literacy we used a relative norm instead, defining the lowest quartile of respondents as low literate and the others as adequate/high literate (further referred to as 'high').

\subsection{Patient activation}

For this study, the Dutch version of the PAM 13 was used [24]. This measure consists of 13 items assessing knowl- edge, skills and confidence for managing one's own health and health care. All items have five possible responses with scores ranging from 0 to 4; not applicable (N/A), disagree strongly, disagree, agree or agree strongly. Participants who filled out less than seven questions or answered all items with disagree strongly or agree strongly were defined as unreliable and excluded from the analysis $[19,20]$. A sum score was calculated with items left blank or answered with not applicable scored as missing. Raw scores were trans- formed into standardized activation scores ranging from

0 to 100 . These activation scores were converted into one of four progressively activation levels (level 1: score <45.2, level 2: score 47.4-52.9, level 3: score 56.466.0, level 4: score >68.5) [19]. The Dutch version of the PAM has shown to be a valid and reliable instrument with good psychometric properties [24]. Internal consistency of the PAM in this study was good (Cronbach's alpha 0.83).

\subsection{Demographic characteristics}

Demographics (age, gender, education, income, and self-reported general health status) of the participants were already known as these characteristics are documented at the start of the panel membership and updated annually. Age was divided in three age groups ( $<39$ years, 40-64 years, and 65+). Educational level was divided in three groups; low (none, primary school or vocational training), middle (secondary or vocational education) and high (professional higher education or university).

\subsection{Statistical analysis}

Differences in all three aspects of provider choice between low and high literate respondents and between the four different PAM-groups were tested using Pearson's $\mathrm{x} 2$. Kendall's tau-b was used as measure of association. In regression analysis, the relative contribution of respectively demographics, health literacy and patient activation on active provider choice ('.. .would you search for information on the basis of which you yourself could select the best hospital or medical specialist?') was explored. We performed a logistic regression analysis, including demo- graphic characteristics (gender, age, education, income, self-reported general health) in model 0 and adding explanatory variables in the other models; health literacy (help with reading, confident filling out medical forms, problems learning about medical condition) in model 1 and health literacy and patient activation (PAM level) in model 2. Statistical software STATA 11.0 was used for analysis. 
Rademakers, J., Nijman, J., Brabers, A.E.M., Jong, J.D. de, Hendriks, M. The relative effect of health literacy and patient activation on provider choice in the Netherlands. Health Policy: 2014, ) 114(2-3), 200-206

\section{RESULTS}

\subsection{Response}

\section{[TABLE 1][TABLE 2]}

A total of 1500 members (75.0\%) returned the question- naire. Most participants were female (54.0\%) and of Dutch origin (93.6\%) (Table 1). Almost 60\% rated their health in general as good. The average age of the respondents was 55.9 years (not in table). A majority (83.6\%) had completed at least secondary or vocational education. With respect to health literacy, the lowest quartile (21.8\%) scored $\leq 8$; we categorized this group as low literate and the other $78.2 \%$ as high. Furthermore, $22.0 \%$ of the respondents scored in the lowest PAM level (level 1), $25.9 \%$ in level 2, 29.8\% in level 3 and $22.2 \%$ in level 4 . There was a significant but weak association between the health literacy and PAM scores of respondents (Table 2; x2 p < 0.001; Kendall's tau-b: 0.161). There were also significant associations between health literacy and educational level (Table 3; x2 p < 0.001; Kendall's tau-b: 0.203) and between patient activation and educa- tional level (Table 3; x2 p < 0.001; Kendall's tau-b: 0.118).

\subsection{Health literacy, patient activation and provider choice}

The majority of our respondents (59.6\%) indicated that, after a referral from their general practitioner, they would not search for information on the basis of which they them- selves could select the best medical specialist or hospital, the remainder four out of 10 (40.4\%) would do so. Analyses show significant differences between low and high liter- ate respondents: whereas $67.6 \%$ of the people with a low literacy level would not look for information, this percent- age was $57.2 \%$ for the high literate (x2 $=11.22 ; \mathrm{p}<0.001$; Kendall's tau-b: 0.087). Comparing respondents in the four levels of patient activation yielded similar results: $66.1 \%$ (level 1) would not look for information, compared to 63.1\% (level 2), 59.0\% (level 3) and 51.3\% (level 4) (x2 = 16.65; $\mathrm{p}<0.001$; Kendall's tau-b: 0.096). The regression analysis illustrates that gender and educational level are the most significant predictors of active provider choice (Table 4): women and higher educated people are more likely to seek information in order to select the best provider or hospital. Adding health literacy to model 0 (model 1) does not produce significant results. People in the highest level of patient activation, however, are significantly more likely to seek information (model 2).

The main reason not to look for information is that many respondents (39.2\%) already know which medical specialist or hospital they want to visit. Another 30.8\% indicates that they do not know where to base their decision on and one in five (20.7\%) does not know how to judge the information.

Low literate respondents less often know which specialist or hospital they want to go to (x2 = 7.57; $\mathrm{p}<0.01$; Kendall's tau-b: -0.094$)$, as do people with lower patient activation levels ( $\mathrm{x} 2=12.56$; $\mathrm{p}<0.01$; Kendall's tau-b: -0.097 ).

There is no difference between low and high literate respondents in the degree to which they know where to base their decision on ( $\mathrm{x} 2=0.653$; $\mathrm{p}<0.42$; Kendall's tau-b: -0.277). There is, however, a significant difference between the different PAM-levels: people in level 1 indicate this reason more often (31.8\%) compared to 
Rademakers, J., Nijman, J., Brabers, A.E.M., Jong, J.D. de, Hendriks, M. The relative effect of health literacy and patient activation on provider choice in the Netherlands. Health Policy: 2014, ) 114(2-3), 200-206

people in level $4(10.3 \%)(x 2=24.61$; $\mathrm{p}<0.001$; Kendall's tau-b: -0.127$)$. With respect to the last reason for not seeking information ('I do not know how to judge the information') neither health literacy ( $\mathrm{x} 2=0.204$; $\mathrm{p}=0.65$; Kendall's tau-b: $-0.016)$ nor patient activation $(\mathrm{x} 2=2.847 ; \mathrm{p}=0.42$; Kendall's tau- $\mathrm{b}$ : -0.051 ) has a significant influence.

\section{[TABLE 3][TABLE 4]}

The vast majority of consumers who do not actively select a provider themselves choose the hospital which or medical specialist that their general practitioner advices them (75.2\%). More than one-third (37.3\%) chooses the hospital or specialist they have good experiences with, and 30.1\% indicates they would select the hospital or provider nearest by. There are no significant differences by health literacy or level of patient activation for any of these reasons.

\section{DISCUSSION}

Though active provider choice by patients has become an important policy goal in recent years, predominantly as a tool to enhance quality of care, patients in general do not seem to go for it. In this study in the Netherlands, almost sixty per cent of the respondents would not search for information on the basis of which they could select the best hospital or medical specialist. Of this group, three- quarters would rely on their general practitioner's advice with respect to which provider to choose. This subgroup is actually larger than the group of 'active choosers' (44.3\% vs. $40.4 \%$ of the total sample respectively).

Our study thus confirms earlier research that only a minority of the population actively searches for information on the basis of which they can make an informed choice for a provider and that more people rely on the choice of their general practitioner for a specific medical specialist or hospital.

We examined the influence of health literacy and patient activation on active provider choice, to establish whether certain groups in our society are less able to take up an active role in this process. Both low literacy and lower patient activation levels were negatively associated with active provider choice. So the hypothesis that the pol- icy focus on active provider choice by patients might lead to inequity and that people with lower levels of literacy and patient activation are at a disadvantage here holds. In the regression analysis, however, gender, education and patient activation proved the most important predictors. That health literacy produced only small differences might be the result of our relative norms for low and high literacy. Even the lowest quartile of the respondents might have fairly adequate reading and writing skills (the functional aspect of health literacy as measured by the SBSQ-D). In the European comparative study [23] the Netherlands scored the best of all eight countries with an extremely low percentage (1.8\%) of inadequate health literacy, which confirms this hypothesis. Different levels of patient activation, which encompasses broader competences necessary to function adequately as active health care consumers, were more equally distributed in the population under study. Thus, because the Netherlands has a relative high level of functional health literacy in the 
Rademakers, J., Nijman, J., Brabers, A.E.M., Jong, J.D. de, Hendriks, M. The relative effect of health literacy and patient activation on provider choice in the Netherlands. Health Policy: 2014, ) 114(2-3), 200-206

general population and because patient activation differentiates better, the latter concept seems more promising to discern sub- groups of patients and health consumers here. In countries where more people lack basic reading and writing skills, however, functional health literacy remains an important topic.

Educational level proved to be the strongest predictor of active provider choice. In our study, health literacy and patient activation are associated with each other. In Nut- beam's model [22], health literacy is defined as an outcome of education, and one of the intermediaries between educational level and health outcomes. The association between education and health literacy might not be caused by differences in cognitive skills only. Greener [12] suggests that "It may well be that factors that are grouped under the heading 'social capital' - educational attainment level, social back- ground, location of residence and professional status - may also affect whether a particular patient will feel comfort- able making choices”. This feeling is an integral part of the patient activation concept. Hibbard and Mahoney [18] confirmed that people with low patient activation levels are more often weighted down by negative emotions and negative self-perception. Improving their activation level might lead to breaking the negative circle, but the steps towards improving health and taking up responsibility have to be small and tailored to their actual possibilities. With respect to active provider choice, this would mean that people in lower activation levels have to get help and guidance in the search for information, both with respect to formulating the questions they might have and indicators they find important as to the places where to look for understandable and reliable information. Since the general practitioner is already a prominent person in the choice process and usually the one who makes the referral, either he or a practise assistant can guide the patients in this process.

A normative question is whether it is a problem that some groups in society are less likely to take up the role of active choosers, and - if so - whose problem it is. From a policy perspective, the question can be raised whether it is necessary that all patients make active choices and switch providers in order to make quality improvements happen, or if it is enough if a minority does so. Small numbers might not influence market shares dramatically, but it may be enough to keep hospital boards and medical specialists alert. It has been described before that the mere publication of quality indicators in public (e.g. on the inter- net) has a direct positive effect on the quality of care, even though patients might not use it [11].

But quality differences between providers and practise variation exists, which still supports the necessity for patients to try to find the specialist or hospital that best meets their needs.

The result of not being willing or able to search for comparative quality information and select the best provider might be that less educated and activated patients end up receiving suboptimal care, thus reinforcing the likelihood of inferior health outcomes. Therefore, from the perspective of equity, there might be a problem. Both general practitioners, health insurers and the Health Inspectorate will have to act as a safety net for these patients. General practitioners can discuss with their patients what they regard as important with respect to a hospital or medical specialist, and take this into account when giving an advice or referral. Health insurers can include quality of care (both medical indicators and patient reported experiences and outcomes) in their care purchasing policy, thus guaranteeing an adequate, patient- 
Rademakers, J., Nijman, J., Brabers, A.E.M., Jong, J.D. de, Hendriks, M. The relative effect of health literacy and patient activation on provider choice in the Netherlands. Health Policy: 2014, ) 114(2-3), 200-206

centred level of care. The Health Inspectorate is responsible for securing the minimal quality standard of care for all citizens.

\subsection{Limitations and strengths}

Since our sample is drawn from a panel, all of the respondents are able to read and write and therefore the percentage of people with inadequate health literacy skills will even be smaller compared to the general population (where it is 1.8\%). We used a relative definition of low versus high literate respondents, which probably lead to smaller differences in our study. A different study sample, in which more people with (very) low literacy skills were included might have led to more pronounced results with respect to the influence of health literacy.

The respondents are asked about presumed, not actual behaviour. This might lead to different answers. Since people know they are supposed to be active health care consumers, it might have led to social desirable answers.

In practice, they would mean that the percentage of active choosers would even be lower.

Since only recently instruments on health literacy and patient activation are translated in Dutch this is the first research in the Netherlands where these two concepts could be studied as predictors of active provider choice. Most studies on health literacy and patient activation have been done in the United States. To our knowledge, none of these studies have looked at the relative effect of health literacy and patient activation on provider choice. Furthermore, given the different social structure and health care systems, it is important that in European countries studies on these topics are done as well.

\section{CONCLUSIONS}

In the Netherlands, after a referral from their general practitioner, six out of every 10 people indicate that they would not search for information on the basis of which they themselves could select the best provider or hospital. Both low literacy and lower patient activation levels were negatively associated with active provider choice. The main predictors of active choice in this study are gender, education and patient activation. The policy focus on active provider choice might result in inequity, with men, less educated and less activated people being at a disadvantage.

\section{REFERENCES}

[1] Berwick DM, James B, Coye MJ. Connections between quality mea- surement and improvement. Medical Care 2003;41(1 Suppl):I30-8.

[2] Brabers AEM, Reitsma-van Rooijen M, de Jong JD. Consumenten- panel Gezondheidszorg: basisrapport met informatie over het panel (2012). Utrecht: NIVEL; 2012.

[3] Dixon A, Le Grand J. Is greater patient choice consistent with equity? The case of the English NHS. Journal of Health Services Research and Policy 2006;11(3):162-6.

[4] Dixon A, Robertson R, Appleby J, Burge P, Devlin N, Magee H. Patient choice: how patients choose and how providers respond. London: The King's Fund; 2010.

[5] Dutch Health Care Insurance Act, http://wetten.overheid.nl/ BWBR0018450; 2005 [accessed 15.03.13]. 
Rademakers, J., Nijman, J., Brabers, A.E.M., Jong, J.D. de, Hendriks, M. The relative effect of health literacy and patient activation on provider choice in the Netherlands. Health Policy: 2014, 114(2-3), 200-206

[6] Dutch Market Regulation Act, http://wetten.overheid.nl/ BWBR0020078; 2006 [accessed 15.03.13].

[7] Exworthy M, Peckham S. Access, choice and travel: implications for health policy. Social Policy and Administration 2010;40(3):267-87.

[8] Fotaki M, Roland M, Boyd A, McDonald R, Scheaff R, Smith L. What benefits will choice bring to patients? Literature review and assessment of implications. Journal of Health Services Research and Policy 2008;13(3):178-84.

[9] Fotaki M. Patient choice and empowerment - what does it take to make it real? A comparative study of choice in the UK and Sweden under the market-oriented reforms. Eurohealth 2010;11(3):3.

[10] Fransen MP, van Schaik TM, Twickler TB, Essink-Bot ML. Applica- bility of internationally available health literacy measures in the Netherlands. Journal of Health Communication 2011;16:134-49.

[11] Fung CH, Lim YW, Mattke S, Damberg C, Shekelle P. Systematic review: the evidence that publishing patient care performance data improves quality of care. Annals of Internal Medicine 2008;148(2):111-23.

[12] Greener I. Are the assumptions underlying patients choice realistic?:a review of the evidence. British Medical Bulletin 2007;83:249-58.

[13] Groenewoud AS. It's your choice! A study of search and selection processes, and the use of performance indicators in different patient groups. Rotterdam: Erasmus Universiteit Rotterdam; 2010.

[14] Grol R, Faber M. Commonwealth Fund International Health Policy Survey 2007. Nijmegen: UMC St Radboud; 2010.

[15] Hibbard JH, Peters E, Dixon A, Tusler M. Consumer competencies and the use of comparative quality information: it isn't just about literacy. Medical Care Research and Review 2007;64:379-94.

[16] Hibbard JH, Mahoney ER, Stockard J, Tusler M. Development and test- ing of a short form of the patient activation measure. Health Services Research 2005;40:1918-30.

[17] Hibbard JH, Cunningham PJ. How engaged are consumers in their health and health care, and why does it matter? Center for Studying Health Systems Change Research Brief 8: October 2008; 2008.

[18] Hibbard JH, Mahoney E. Toward a theory of patient and consumer activation. Patient Education and Counseling 2010;78:377-81.

[19] Insignia Health. Patient Activation Measure (PAM) 13 License Mate- rials. Insignia Health 2010.

[20] Maindal HT, Sokolowski I, Vedsted P. Translation, adaptation and validation of the American short form Patient Activation Mea- sure (PAM13) in a Danish version. BMC Public Health 2009;9: 209.

[21] Nijman J, Hendriks M, Brabers A, de Jong J, Rademakers J. Patient activation and health literacy as predictors of health information use in a general sample of Dutch health care consumers. Journal of Health Communication 2013 (in press).

[22] Nutbeam D. Health literacy as a public health goal: a challenge for contemporary health education and communication strategies into the 21st century? Health Promotion International 2000;15(3):259-67.

[23] Pelikan J, Röthlin F, Ganahl K, on behalf of the HLS-EU consortium. Comparative report on health literacy in eight EU member states (The European Health literacy Project HLSEU 2009-2012), Wien; 2012.

[24] Rademakers J, Nijman J, Heijmans M, Rijken M. Measuring patient activation in the Netherlands: translation and validation of the American short form Patient Activation Measure (PAM13). BMC Public Health 2012;12:577, http://dx.doi.org/10.1186/1471-245812-577.

[25] Robinson JC, Ginsburg PB. Consumer-driven health care: promise and performance. Health Affairs 2009;28(2):w272-81.

[26] Thomson S, Dixon A. Choices in health care: the European experience. Journal of Health Services Research and Policy 2006;11(3):167-71.

[27] Varkevisser M, van der Geest SA. Why do patients bypass the nearest hospital? An empirical analysis for orthopaedic care and neurosurgery in the Netherlands. European Journal of Health Economics 2007;8(3):287-95. 
Rademakers, J., Nijman, J., Brabers, A.E.M., Jong, J.D. de, Hendriks, M. The relative effect of health literacy and patient activation on provider choice in the Netherlands. Health Policy: 2014, 114(2-3), 200-206

\section{TABLES}

Table 1

Demographic characteristics of the respondents.

\begin{tabular}{|c|c|c|c|}
\hline & $N$ & & $\%$ \\
\hline Age & 1500 & & \\
\hline $18-39$ years & & 339 & 22.6 \\
\hline 40-64 years & & 627 & 41.8 \\
\hline$\geq 65$ years & & 534 & 35.6 \\
\hline Gender & 1500 & & \\
\hline Male & & 690 & 46.0 \\
\hline Female & & 810 & 54.0 \\
\hline Education & 1447 & & \\
\hline Low & & 237 & 16.4 \\
\hline Middle & & 865 & 59.8 \\
\hline High & & 345 & 23.8 \\
\hline Ethnicity & 1496 & & \\
\hline Dutch & & 1401 & 93.6 \\
\hline Other & & 95 & 6.4 \\
\hline Self-reported health & 1476 & & \\
\hline Poor & & 19 & 1.3 \\
\hline Bad & & 225 & 15.2 \\
\hline Good & & 873 & 59.2 \\
\hline Very good & & 270 & 18.3 \\
\hline Excellent & & 89 & 6.0 \\
\hline
\end{tabular}

Table 2

Relationship between health literacy and PAM $(N=1418)$.

\begin{tabular}{lrrrrr}
\hline & \multicolumn{2}{c}{ Low literacy } & & \multicolumn{2}{c}{ High literacy } \\
\cline { 2 - 3 } \cline { 6 - 6 } & \multicolumn{1}{c}{$N$} & & & $N$ & $\%$ \\
\hline Level 1 (low) & 104 & $34.3 \%$ & & 208 & $18.6 \%$ \\
Level 2 & 84 & $27.7 \%$ & & 284 & $25.5 \%$ \\
Level 3 & 78 & $25.8 \%$ & & 348 & $31.2 \%$ \\
Level 4 (high) & 37 & $12.2 \%$ & 275 & $24.7 \%$ \\
Total & 303 & $100 \%$ & & 1115 & $100 \%$ \\
\hline
\end{tabular}


Rademakers, J., Nijman, J., Brabers, A.E.M., Jong, J.D. de, Hendriks, M. The relative effect of health literacy and patient activation on provider choice in the Netherlands. Health Policy: 2014, ) 114(2-3), 200-206

Table 3

Relationship between education, health literacy $(N=1430)$, and patient activation level $(N=1394)$.

\begin{tabular}{|c|c|c|c|c|c|c|}
\hline & Low education & & Medium education & & High & \\
\hline Low literacy & 89 & $38.0 \%$ & 183 & $21.4 \%$ & 33 & $9.7 \%$ \\
\hline High literacy & 145 & $62.0 \%$ & 674 & $78.7 \%$ & 306 & $90.3 \%$ \\
\hline Total & 234 & $100 \%$ & 857 & $100 \%$ & 339 & $100 \%$ \\
\hline Level 1 (low) & 70 & $31.4 \%$ & 178 & $21.2 \%$ & 53 & $16.1 \%$ \\
\hline Level 2 & 52 & $23.3 \%$ & 233 & $27.7 \%$ & 77 & $23.3 \%$ \\
\hline Level 3 & 71 & $31.8 \%$ & 246 & $29.2 \%$ & 104 & $31.5 \%$ \\
\hline Level 4 (high) & 30 & $13.5 \%$ & 184 & $21.9 \%$ & 96 & $29.1 \%$ \\
\hline Total & 223 & $100 \%$ & 841 & $100 \%$ & 330 & $100 \%$ \\
\hline
\end{tabular}

Table 4

Logistic regression of active provider choice $(N=1479)$.

\begin{tabular}{|c|c|c|c|}
\hline & OR model 0 & OR model 1 & OR model 2 \\
\hline Male & Reference & Reference & Reference \\
\hline Female & 1.47 & 1.47 & 1.47 \\
\hline Age $<39$ & Reference & Reference & Reference \\
\hline Age $>65$ & 0.79 & 0.77 & 0.79 \\
\hline Low education & Reference & Reference & Reference \\
\hline Medium education & 1.68 & 1.62 & 1.60 \\
\hline Medium income ( $1750-2500$ euro) & 1.02 & 0.99 & 0.97 \\
\hline High income (>2500 euro) & 1.19 & 1.19 & 1.18 \\
\hline Poor/bad self-reported health & Reference & Reference & Reference \\
\hline Good self-reported health & 0.84 & 0.85 & 0.81 \\
\hline Very good/excellent self-reported health & 0.93 & 0.94 & 0.82 \\
\hline Low health literacy & - & Reference & Reference \\
\hline High health literacy & - & 1.18 & 1.12 \\
\hline
\end{tabular}

Model 0: including gender, age, education, income and self-reported general health; model 1: model 0+health literacy; Model 2: model 1+patient activation; - not applicable; bold: $p<0.05$. 